\title{
SUGESTÕES PARA O ALCANCE DAS DIMENSÕES DA SUSTENTABILIDADE NO TRATAMENTO DOS CONHECIMENTOS TRADICIONAIS ASSOCIADOS À BIODIVERSIDADE AMAZÔNICA
}

Ana Carolina Couto Matheus ${ }^{1}$

Recebido em 25/07/2019

Aprovado em 07/07/2020

\section{RESUMO}

O objeto do trabalho em testilha é estudar as dimensões da sustentabilidade associada aos respectivos problemas e sugerir o alcance da sustentabilidade dos conhecimentos tradicionais associados à biodiversidade amazônica, considerando a imprescindível inter-relação dos conhecimentos tradicionais dos povos da Amazônia com a sustentabilidade. Comporta necessariamente um tratamento transdisciplinar, pois as categorias de construções da realidade são diversas, e, embora diferentes, encontram-se profundamente interligadas ou interdependentes. O método utilizado na fase de investigação e na fase de tratamento dos dados foi o indutivo. Nas diversas fases da pesquisa foram acionadas as técnicas do referente, da categoria, do conceito operacional, da pesquisa bibliográfica e do fichamento. $\mathrm{O}$ desenvolvimento do tema pautou-se pela persecução dos objetivos geral e específicos que nortearam a produção. O relatório se encerra com as conclusões e consubstancia o resultado de todos os achados da pesquisa acadêmica, findando por confirmar a hipótese inicialmente concebida, tendo, alfim, alcançado as sugestões para o alcance da sustentabilidade dos conhecimentos tradicionais associados à biodiversidade amazônica.

Palavras-chave: Conhecimentos Tradicionais Associados à Biodiversidade Amazônica. Dimensão Ambiental. Dimensão Econômica. Dimensão Social. Alcance da Sustentabilidade.

\section{SUGGESTIONS FOR REACHING SUSTAINABILITY DIMENSIONS IN}

\section{TREATMENT OF TRADITIONAL KNOWLEDGE ASSOCIATED WITH AMAZON}

\section{BIODIVERSITY}

\section{ABSTRACT}

The object of this work is to study the dimensions of sustainability associated with the respective problems and to suggest the scope of sustainability of traditional knowledge associated with amazonian biodiversity, considering the indispensable interrelationship of traditional knowledge of the peoples of the Amazon with sustainability. It necessarily entails transdisciplinary treatment, since the categories of constructions of reality are

\footnotetext{
${ }^{1}$ Doutora em Ciência Jurídica pela UNIVALI-SC. Mestre em Direito pela UNIPAR-PR. Especialista em Direito Tributário pela UnP-RN. Pós-graduada em Direito Constitucional pela UVB-SP. Graduada em Direito pela TOLEDO-SP. Professora Adjunta III do CCJSA da UFAC-AC. Coordenadora do Núcleo de Prática Jurídica e Estágios. Professora da Pós-Graduação. Orientadora. Conferencista. Conselheira Editorial. Pesquisadora. Advogada. Consultora Jurídica. E-mail: carolcoutomatheus@hotmail.com.
} 
diverse, and although different, they are deeply interconnected or interdependent. The method used in the research phase and in the data processing phase was inductive. In the various phases of the research the techniques of referent, category, operational concept, bibliographic research and file were used. The development of the theme was guided by the pursuit of the general and specific objectives that guided the production. The report concludes with the conclusions and substantiates the results of all the findings of the academic research, eventually confirming the hypothesis initially conceived, and, finally, reached the suggestions for achieving the sustainability of traditional knowledge associated with amazonian biodiversity.

Keywords: Traditional Knowledge Associated with Amazonian Biodiversity. Environmental Dimension. Economic Dimension. Social Dimension. Scope of Sustainability.

\section{INTRODUÇÃO}

Considerando a imprescindível inter-relação dos conhecimentos tradicionais dos povos da Amazônia com a sustentabilidade, o objeto basilar do presente trabalho é estudar as dimensões da sustentabilidade associada aos respectivos problemas e sugerir o alcance da sustentabilidade dos conhecimentos tradicionais associados à biodiversidade amazônica.

Justifica-se a escolha do tema justifica-se em razão da importância e complexidade. Comporta necessariamente um tratamento transdisciplinar, uma vez que as categorias de construções da realidade são diversas, e, embora diferentes, encontram-se profundamente interligadas ou interdependentes.

O problema da pesquisa em tela é evidenciar os problemas relacionados à dimensão ambiental, econômica e social da sustentabilidade e sugerir o alcance da sustentabilidade dos conhecimentos tradicionais associados à biodiversidade amazônica.

O trabalho todo se encontra parametrizado teoricamente na Constituição da República Federativa do Brasil de 1988 (CRFB/88), na legislação nacional e estrangeira, em vasta literatura nacional e estrangeira, artigos de revistas jurídicas especializadas e jurisprudência pertinente ao tema.

Para o equacionamento do problema suscita-se a seguinte hipótese, a saber: a dimensão ambiental da sustentabilidade está associada ao problema dos riscos à biodiversidade amazônica, a dimensão econômica relaciona-se à biopirataria e a apropriação indevida dos conhecimentos tradicionais e a dimensão social associa-se aos problemas relacionados à saúde e a qualidade de vida dos povos tradicionais da Amazônia.

Em função da problemática e da hipótese, o objetivo geral do trabalho consiste em analisar o alcance da sustentabilidade dos conhecimentos tradicionais associados à biodiversidade amazônica, considerando a imprescindível inter-relação dos conhecimentos tradicionais dos povos da Amazônia com a conservação ambiental. 
A hipótese retromencionada impulsionou o desenho dos seguintes objetivos específicos para se alcançar os achados pretendidos: estudar as dimensões ambiental, econômica e social da sustentabilidade dos conhecimentos tradicionais associados à biodiversidade amazônica; enfatizar os riscos à biodiversidade amazônica, a biopirataria, a apropriação indevidade dos conhecimentos tradicionais, a saúde e a qualidade de vida dos povos tradicionais da Amazônia, ou seja, os problemas relacionados às dimensões da sustentabilidade; sugerir o alcance da sustentabilidade no tratamento dos conhecimentos tradicionais associados à biodiversidade amazônica.

O marco de referência privilegia a construção teórica segundo a qual estuda o tripé dimensional da sustentabilidade, desdobra-se por meio do estudo dos problemas relacionados a dimensão ambiental, econômica e social da sustentabilidade e verifica a possibilidade do alcance da sustentabilidade dos conhecimentos tradicionais dos povos amazônicos, por meio do equilíbrio, da cooperação e da educação ambiental.

Pelo método de abordagem indutivo, fonte de pesquisa bibliográfica e legal relativa aos conhecimentos tradicionais associados à biodiversidade amazônica serão pesquisadas e confrontadas as partes de um todo para que se possa ter uma visão generalizada. Durante as diversas fases da pesquisa serão utilizadas as técnicas do referente, da categoria, do conceito operacional, do fichamento e com base em documentação indireta será realizada a pesquisa bibliográfica.

O trabalho em apreço finda com as conclusões, em que serão apresentados pontos conclusivos abstraídos da pesquisa, a análise e a inferência das reflexões realizadas em relação ao alcance da sustentabilidade dos conhecimentos tradicionais associados à biodiversidade amazônica.

\section{AS DIMENSÕES DA SUSTENTABILIDADE E OS CONHECIMENTOS}

\section{TRADICIONAIS ASSOCIADOS À BIODIVERSIDADE AMAZÔNICA}

Segundo Boff (2012, p. 107) sustentabilidade é toda ação destinada a manter as condições que sustentam todos os seres e a vida humana, visando sua continuidade e ainda atender as necessidades da geração presente e das futuras, de tal forma que o capital natural seja mantido e enriquecido em sua capacidade de regeneração, reprodução e coevolução.

\footnotetext{
El paradigma actual de la Humanidad es la sostenibilidad. La voluntad de articular una nueva sociedad capaz de perpetuarse en el tiempo en unas condiciones dignas. El deterioro material del planeta es insostenible, pero también es insostenible la miseria y la exclusión social, la injusticia y la opresión, la esclavitud y la dominación cultural y económica (FERRER, 2012, p. 319).
}

Historicamente, a sustentabilidade foi edificada a partir do tripé dimensional ambiental, econômico e social, ou, como denominado por Canotilho (2010), “dimensão tridimensional”, com 
grande influência da Declaração do Milênio, realizada em 2000, que proclamou a Declaração e Objetivos do Milênio para o Desenvolvimento.

Há que se consignar que inúmeros autores vislumbram outras dimensões da sustentabilidade. Freitas vislumbra cinco dimensões, a saber: ambiental, econômica, social, jurídicopolítica e ética. Dimensões "intimamente vinculadas, componentes essenciais à modelagem do desenvolvimento. De fato. Condicionam-no. Moldam-no. Tingem-no. Humanizam-no. Ecologizamno. Fazem-no duradouro, continuado, sinergético, estimulante, inclusivo e vinculante" (FREITAS, 2012, p. 67).

Ao discorrer acerca da dimensão jurídico-política, Freitas impõe ao Estado que garanta ao povo a tutela jurídica do direito a um meio ambiente saudável, tanto para a presente quanto para as futuras gerações:

A dimensão jurídico-política ecoa o sentido de que a sustentabilidade determina, com eficácia direta e imediata, independentemente de regulamentação, a tutela jurídica do direito futuro e, assim, apresenta-se com dever constitucional de proteger a liberdade de cada cidadão (titular de cidadania ambiental ou ecológica), nesse status, no processo de estipulação intersubjetiva do conteúdo intertemporal dos direitos fundamentais das gerações presentes e futuras, sempre que viável diretamente (FREITAS, 2001, p. 19).

Em relação à dimensão ética da sustentabilidade, Jamieson (2010, p. 7) ensina que "existe de fato o dever ético indeclinável e natural de sustentabilidade ativa, que não instrumentaliza predatoriamente, mas intervém para restaurar o equilíbrio dinâmico". Antes de definir ética sustentável, Emery justifica sua existência:

\begin{abstract}
A necessidade de se repensar o agir humano para torná-lo sustentável decorre da intensidade da utilização dos recursos naturais e da velocidade com a qual o homem vem transformando seu meio, que é muito maior do que a capacidade da natureza de se reorganizar, e pelo largo espectro temporal dos efeitos da ação humana, que superam em muito o poder de previsão de consequências, de forma que o poder de ação é sempre superior à capacidade de previsão de seus efeitos. Sustentabilidade está relacionada, nesse sentido, com atitude, comportamento, para consigo, terceiros, a natureza e o futuro. Tal assertiva implica um "viés" ético que supera a ética e a moral clássica, uma vez que impõe deveres não só para com o aqui e agora, mas com a universalidade das coisas presentes e futuras (EMERY, 2016, p. 75).
\end{abstract}

Em obra dedicada à sustentabilidade, Sachs (2007, p. 71-86) vislumbra oito dimensões da sustentabilidade: social, cultural, ecológica, ambiental, territorial, econômica, política-nacional e política-internacional.

Para Cruz e Bodnar sustentabilidade é um paradigma indutor do direito à medida que sistematiza normas protetivas do ambiente para além da ciência jurídica e em escala global, tendo como base forte o meio ambiente, vislumbram a sustentabilidade em múltiplas dimensões que incluam as variáveis ecológica, social, econômica e tecnológica.

$\mathrm{Na}$ perspectiva jurídica, todas estas dimensões apresentam identificação com a base de vários direitos fundamentais, aí incluídos o meio ambiente, desenvolvimento 
sustentável, direitos prestacionais sociais, dentre outros, cada qual com as suas peculiaridades e riscos. Pela importância e centralidade na ordem política atual, é possível afirmar assim que a sustentabilidade pode ser compreendida como impulsionadora do processo de consolidação de uma nova base axiológica ao Direito (CRUZ e BODNAR, 2011, p. 81).

$\mathrm{Na}$ atual sociedade do conhecimento, “é imprescindível que também seja adicionada a dimensão tecnológica, pois é a inteligência humana individual e coletiva acumulada e multiplicada que poderá garantir um futuro sustentável" (CRUZ e BODNAR, 2012, p. 112).

$\mathrm{Na}$ convicção de Ferrer, o direito à sustentabilidade é pensado para resolver problemas globais, visualiza dimensões que estão além do triângulo ambiental, econômico e social. Nesse sentido, o autor vem promovendo pesquisas que exponenciam a relevância da dimensão tecnológica para argumentar que somente por meio da inteligência humana individual e coletiva acumulada e multiplicada é que se poderá assegurar um futuro mais sustentável:

A mi juicio, el triángulo que definirá nuestro futuro es el formado por el medio
ambiente, la sociedad y la técnica. De hecho, la técnica de la que dispongamos es la
que marcará las acciones que podamos poner en marcha para corregir, si es que
llegamos a tiempo, el rumbo actual decididamente abocado a la catástrofe. Y la
técnica, también, define y ha definido nuestros modelos sociales. La rueda, las
técnicas de navegación, el acero, la máquina de vapor, la electricidad, el automóvil o
la televisión han definido y conformado nuestras estructuras sociales. Internet, las
nanotecnologías y lo que está por llegar, también lo harán. La sociedad del futuro será
lo que a través de la ingeniería social seamos capaces de construir institucionalmente
y lo que la ciencia y la técnica permitan o impongan. En todo caso, lo que también es
evidente es que precisamos urgentemente de un rearme ético capaz de orientar estos
procesos hacia un auténtico progreso civilizatorio basado en valores positivos. La
ciencia, sumada al egoísmo a ultranza, lo que genera es barbárie (FERRER, 2012, p.
320).

A sustentabilidade é concebida em suas múltiplas ou plurais dimensões, ainda que não exista uniformização conceitual do seu termo parece evidente, pela vasta literatura que envolve a matéria, que ela é um "valor" (FREITAS, 2014, p. 32), um "princípio" (BOSSELMANN, 2015; CRUZ e GLASENAPP, 2014; FREITAS, 2014; SILVA, 2010) e um "direito fundamental" (COIMBRA, 2017).

O trabalho em tela adota a classificação dimensional da sustentabilidade categorizada por Freitas (2012, p. 58-70) cujas dimensões incidem, de forma lógica e imbricada no tratamento sustentável dos conhecimentos tradicionais associados à biodiversidade amazônica.

A dimensão ambiental da sustentabilidade para Lima e Pozzobon (2005, p. 45) é a "capacidade de uma dada população de ocupar uma determinada área e explorar seus recursos naturais sem ameaçar, ao longo do tempo, a integridade ecológica do meio ambiente". Para Silva (2010, p. 18) "é a interação do conjunto de elementos naturais, artificiais e culturais que propiciem o desenvolvimento equilibrado da vida em todas as suas formas".

A dimensão ambiental é substrato da própria história e da relação do homem com a 
natureza ao longo dos séculos. O uso predatório dos recursos ambientais por parte dos homens, associado às tragédias ambientais obrigaram o debate sob o novo enfoque, repensando as bases capitalistas de exploração do meio ambiente.

Na concepção de Garcia (2011, p. 40) a dimensão econômica da sustentabilidade trata do desenvolvimento da economia com a finalidade de gerar melhoria na qualidade de vida das pessoas, com padrões que contenham o menor impacto ambiental possível. O "desenvolvimento harmônico da economia e ecologia que devem ser ajustados numa correlação de valores onde o máximo econômico reflita igualmente um máximo ecológico" (DERANI, 2008, p. 128).

Garcia (2011, p. 164) adverte que é impossível discutir a sustentabilidade econômica de forma dissociada da ambiental. Para Freitas (2012) a pobreza, a miséria, a ausência de saneamento básico e tudo mais que comprometa a dignidade humana por ausência de recursos materiais mínimos à saudável qualidade de vida, não é sustentável.

A dimensão econômica da sustentabilidade visa ao desenvolvimento da economia com a finalidade de gerar melhor qualidade de vida às pessoas. Passou a ser considerada no contexto da sustentabilidade porque não haveria possibilidade de retroceder nas conquistas econômicas de desenvolvimento alcançadas pela sociedade mundial; e o desenvolvimento econômico estaria interligado com a dimensão social do princípio da sustentabilidade, pois é necessário para a diminuição da pobreza.

A dimensão social da sustentabilidade é o capital humano, aspecto social relacionado às qualidades dos seres humanos. Baseada no processo de melhoria da qualidade de vida da sociedade, pela redução das discrepâncias entre a opulência e a miséria, como nivelamento de padrão de renda, acesso à educação, moradia, alimentação, ou seja, da garantia mínima dos direitos sociais previstos na CRFB.

Na concepção de Garcia (2011, p. 210-215) a dimensão social implica em melhoria na qualidade de vida da coletividade, na redução da discrepância oriunda da injusta distribuição de renda, ligada à garantia dos direitos sociais e da dignidade da pessoa humana. Com lastro teórico nas grandes conferências globais sobre o meio ambiente, a referida autora sustenta que a pobreza é um dos grandes desastres da humanidade. Os privados do mínimo existencial à sua sobrevivência não têm garantido direitos sociais básicos do art. $6^{\circ}$ da CRFB. Negar a dignidade humana aos que vivem em extrema pobreza contribui para que depredem o meio ambiente.

Segundo Neves (2011, p. 17) "o conceito de sustentabilidade social caracteriza-se pela melhoria da qualidade de vida da população, equidade na distribuição de renda e de diminuição das diferenças sociais, com participação e organização popular".

Para Sachs (2002, p. 85-89) a dimensão social se refere ao "alcance de um patamar 
razoável de homogeneidade social, com distribuição de renda justa, emprego pleno e/ou autônomo com qualidade de vida decente e igualdade no acesso aos recursos e serviços sociais". Mencionado autor se refere à concretude dos direitos sociais.

\title{
2 OS PROBLEMAS RELACIONADOS AO TRIPÉ DIMENSIONAL DA
} SUSTENTABILIDADE

Os problemas relacionados à dimensão ambiental da sustentabilidade são os riscos à biodiversidade amazônica. A diversidade biológica dos países amazônicos é um patrimônio que merece ser protegido, representa valiosa alternativa ao desenvolvimento sustentável nos planos local, nacional e sub-regional. $\mathrm{O}$ art. $2^{\circ}$ da $\mathrm{CDB}$ define diversidade biológica como a variabilidade de organismos vivos de todas as origens, compreendendo os ecossistemas terrestres, marinhos e outros ecossistemas aquáticos e os complexos ecológicos de que fazem parte; a diversidade dentro de espécies, entre espécies e de ecossistemas.

Para Santilli conhecimentos tradicionais (CTs) são componentes intangíveis da biodiversidade e podem ser representados nas "práticas, inovações e conhecimentos desenvolvidos pelos povos indígenas, quilombolas e populações tradicionais, relevantes à conservação e utilização sustentável da diversidade biológica”. Os CTs compreendem técnicas de manejo de recursos naturais, métodos de caça e pesca, conhecimentos sobre ecossistemas e propriedades farmacêuticas, alimentícias e agrícolas de espécies e as próprias categorizações e classificações de espécies de flora e fauna utilizadas pelos povos tradicionais.

Segundo Dias (2002, p. 20) a biodiversidade compõe a qualidade ambiental e "qualquer perda de diversidade biológica, seja no nível de ecossistemas, espécies ou populações, representa uma perda de qualidade ambiental".

\begin{abstract}
As queimadas, o desmatamento para extração de madeira ilegal, os avanços da pecuária e da agricultura de larga escala, a mineração, as sobreposições fundiárias, a abertura de estradas, o planejamento e a construção de grandes barragens e, mais recentemente, a consideração da exploração petrolífera ameaçam a integridade do bioma. Esforços, ainda não efetivamente coordenados, para a conservação e uso sustentável dos recursos florestais compõem o cenário de ocupação e se propõem a modificar, ainda que timidamente, estratégias de desenvolvimento para a Amazônia que estão voltadas exclusivamente para o crescimento econômico (SILVEIRA, 2017, p. 19-20).
\end{abstract}

O desmatamento reduz a biodiversidade, causa erosão dos solos, degrada áreas de bacias hidrográficas, libera gás carbônico para a atmosfera, reduz a umidade do ar, causa desequilíbrio social, econômico e ambiental. As consequências e os impactos do desmatamento são sentidos em nível planetário. 
A floresta amazônica se comporta como um enorme reservatório de carbono atmosférico. Durante o seu crescimento, as árvores removem enormes quantidades de gás carbônico da atmosfera, metade da biomassa das árvores é constituída de carbono. Com o desmatamento, todo esse carbono é reemitido para a atmosfera, o que contribui ainda mais para o aumento do efeito estufa.

A devastação da Amazônia relaciona-se à estrutura econômica do país. Dessa forma, torna-se difícil a aplicação da legislação ambiental interna, dificuldade que é potencializada pela deficiência da própria estrutura vinculada à aplicação das normas ambientais. É possível desenvolver e ao mesmo tempo cumprir critérios que indiquem uma postura sustentável que seja ecologicamente correta, viável e socialmente justa. Para tanto, é importante criar unidades de conservação de uso sustentável, determinada pelo Sistema Nacional de Unidades de Conservação, que estimula o uso sustentável da floresta.

Há sérios riscos na exploração predatória da biodiversidade, pois a destruição do patrimônio genético levará a graves consequências para a humanidade, como o aumento de doenças epidêmicas e respiratórias, desastres naturais, fome e o surgimento de uma situação equivalente ao inverno nuclear.

Os problemas relacionados à dimensão econômica da sustentabilidade são a biopirataria e a apropriação do conhecimento tradicional (CT). O conhecimento tradicional associado (CTA) é uma inovação, na medida em que este conhecimento possa representar um possível desenvolvimento de produto ou processo inovador. Aquele que detêm tal conhecimento é um agente inovador, merecedor de uma recompensa que o fará continuar sendo um inovador e representa uma justa retribuição pelos esforços por ele empreendidos, neste caso pela guarda e compartilhamento deste conhecimento, muitas vezes ancestral

A CRFB, a CDB e o Protocolo de Nagoia reconhecem o CT e preveem a necessidade de sua recompensa. A partir da CDB o mundo passou a debater e sistematizar uma legislação que pudesse reconhecer este direito e, de alguma forma, normatizar sua ocorrência e proteção.

As empresas de biotecnologia e as comunidades indígenas têm formas distintas de conceber a natureza. Para os povos tradicionais a própria espécie da natureza possui valores de uso, simbólicos e culturais, compondo suas mitologias, enquanto as empresas de biotecnologias reduzem o valor do recurso a uma fórmula química do extrato retirado da natureza, a nível molecular. Em 1995, a apelação de um caso de patente utilizou como exemplo o quinino:

Os índios da Amazônia sabem há séculos que a casca da cinchona pode ser usada para tratar malária e outras febres. Eles a usavam em pó. Em 1820, cientistas franceses descobriram que o ingrediente ativo, um alcalóide chamado quinino, poderia ser extraído e usado mais eficazmente na forma de sulfato do alcalóide $\left(\mathrm{C}^{20} \mathrm{H}^{24} \mathrm{~N}^{2} \mathrm{O}^{2}\right)$. Os índios conhecem o quinino? Meus senhores, não importa que prefiram classificá-lo em termos anímicos em vez de químicos. Eles sabem que a casca tem uma qualidade 
que a torna boa para febres e essa é uma descrição do quinino. Por outro lado, em um contexto diferente, o índio da Amazônia não sabe sobre o quinino. Se lhe mostrassem pílulas de sulfato de quinino, ele não as associaria à casca da cinchona. Ele não conhece o quinino sob a descrição de uma substância em forma de pílulas. E certamente não saberia sobre o alcalóide artificialmente sintetizado (DUTFIELD, 2004, p. 76-77).

Patente é propriedade individual de determinado produto ou conhecimento ao titular que obteve seu registro. Os conhecimentos, inovações e práticas dos povos tradicionais não são individuais, mas de um grupo comunitário. A impossibilidade de propriedade individual do CT demanda a criação de alternativas, porque a produção de biotecnologias fundadas em recursos naturais de territórios indígenas e nos CTs torna inevitável o contato entre as sociedades industriais e as comunidades tradicionais.

Referido contato pode manter-se exploratório com a constituição de uma relação de subordinação ou pode ser sustentável, à medida que compreenda a maneira de viver das comunidades tradicionais, confira legitimidade de participação no processo de decisão dos usos tradicionais dessas comunidades e compartilhe os benefícios da utilização da biodiversidade com os povos tradicionais.

A riqueza genética da Amazônia vem sendo usurpada por patentes sobre produtos obtidos a partir da biodiversidade e do CTA. Inexiste repartição de benefícios com as comunidades locais envolvidas no desenvolvimento da invenção. $\mathrm{O}$ acelerado potencial de exploração da biodiversidade e a emergência de novos regimes de propriedade individual criam conflitos relativos à propriedade e uso do patrimônio genético de uma localidade. A revolução biotecnológica e a cobiça por sua matériaprima, o patrimônio genético, têm aumentado a frequência do saque e da usurpação das riquezas biológicas de países como o Brasil, principalmente pela vulnerabilidade institucional e tecnológica.

Biopirataria é o uso de patrimônio genético de um país por empresas multinacionais para atender fins industriais, explorando, indevidamente e clandestinamente, sua fauna ou sua flora, sem pagar por essa matéria-prima. Ao longo dos séculos, a Amazônia tem sido cobiçada por muitos países.

Para Laplante (2004, p. 89) o interesse internacional pela diversidade humana e a biodiversidade vai ao encontro do interesse dos povos locais de obter os benefícios de uma biotecnologia cosmopolita, por meio de uma múltipla e favorável permuta de saberes e habilidades. Entretanto, a maioria das empresas estrangeiras e pesquisadores não repartem os dividendos auferidos com a patente de produtos que utilizam patrimônio genético amazônico.

Stefanello (2005, p. 170) explica que laboratórios desenvolvem medicamentos com uso de plantas medicinais encontradas na Amazônia, a partir do estudo de uma medicina indígena, secularmente construída por meio da sabedoria de inúmeras gerações ancestrais. Usurpação do patrimônio genético e da sabedoria popular dos povos nativos da região amazônica. Os caçadores de plantas estão abrindo caminhos para os prospectores genéticos. 
Multinacionais financiam expedições pelo Hemisfério Sul na busca de exóticas e raras amostras genéticas com lucrativo valor comercial. São inúmeros os casos de biopirataria do patrimônio genético amazônico. A Amazônica engloba outros países sul-americanos, razão pela qual alguns casos de biopirataria envolvem mais de um país.

Os problemas relacionados à dimensão social da sustentabilidade compreendem a saúde e a qualidade de vida dos povos tradicionais da Amazônia. $\mathrm{O}$ cuidado à biodiversidade amazônica envolve outras formas de valorização distintas da exploração comercial, porque os CTs são expressões culturais dos povos tradicionais da Amazônia, ensinados de geração a geração como prática de vida e estão integrados na identidade comunitária desses povos.

Na concepção de Guattari (1990, p. 54-55) se os países latino-americanos pretendem a proteção da biodiversidade que abarque as dimensões sócio-culturais, devem construir novas formas de valorização das atividades humanas, na perspectiva de uma ecosofia.

A sustentabilidade surge como novo paradigma axiológico transnacional, mais ético,
solidário e humano, como tentativa de resposta à crise socioambiental criada pelo
próprio homem na sua relação com a natureza. A sustentabilidade, assim, exige uma
mudança de mentalidade com vistas à construção de uma nova ordem econômica
(mais equilibrada), social (mais justa) e ambiental (que proteja a vida humana na Terra
de forma sustentável e digna) (SOUZA e REZENDE, 2017, p. 12).

Para a ressingularização do homem para o pensar emancipatório, de forma que sua conduta individual agregue valores não só econômicos, mas seja comprometida com o grupo social. À medida que sua subjetividade tenha o sentido de pertencimento ao grupo, a sua relação com a natureza adquire possibilidades de valorizações éticas, estéticas e sociais, podendo reinventá-la e superar a crise ambiental.

\section{SUGESTÕES PARA O ALCANCE DAS DIMENSÕES DA SUSTENTABILIDADE} NO TRATAMENTEO DOS CONHECIMENTOS TRADICIONAIS ASSOCIADOS À

\section{BIODIVERSIDADE AMAZÔNICA}

Para o alcance da sustentabilidade dos conhecimentos tradicionais associados à biodiversidade amazônica sugere-se: a cooperação, a solidariedade, o equilíbrio e a educação ambiental. Cooperação é instrumento para proteger direitos humanos e integra países. Possibilita a conservação e utilização sustentável dos conhecimentos tradicionais associados. No cenário internacional de interdependência Kinoshita (1999, p. 57) explica que há “dever de cooperação para atingir o desenvolvimento mundial".

A cooperação internacional para o desenvolvimento é a alternativa proposta como 
caminho possível de transformação deste quadro, fortemente marcado pela interdependência. Nesse sentido Keohane (2005, p. 31) elaborou uma teoria em torno da cooperação internacional, salientando aspectos de grande importância para o estudo deste tema e que não devem ser desprezados, principalmente quando se busca tal alternativa como resposta ao problema pesquisado.

Admite a possibilidade de cooperação, mesmo em um cenário internacional onde não exista uma potência hegemônica, afastando princípios clássicos do realismo, sendo necessário agregar ao realismo a ênfase nas instituições internacionais que exercem um papel importante na ampliação do alcance da cooperação entre Estados, entre Estados e Organizações Internacionais e entre Organizações Internacionais afins.

Considerando que biopirataria é uma prática que viola os direitos humanos, parte-se para uma construção teórica de cunho crítico que busca fundamentos para definir um novo caminho a ser traçado nas relações internacionais entre os países em desenvolvimento e os países desenvolvidos.

Para ser possível alcançar a sustentabilidade dos CTAs à biodiversidade amazônica, é necessário cooperação que remete ao estudo da solidariedade. Para Martín Mateo (2002, p. 57) solidariedade é um condicionamento para o desenvolvimento sustentável, sob pena dos nossos descendentes terem dificuldades progressivas para assimilar o legado ambiental e os riscos sociais que lhes transmitiremos. A solidariedade é o fundamento ético e princípio jurídico vetor da sustentabilidade.

Equilíbrio significa harmonia, estabilidade, solidez e proporção. É a base da educação, é a busca de outro mundo possível para a vida com qualidade. $\mathrm{O}$ desrespeito ao equilíbrio da natureza cobra altíssimo preço. Para Gadotti (2000, p. 78) o "equilíbrio dinâmico com o outro e com o meio, (...) é harmonia entre os diferentes" e sugestão de alcance da sustentabilidade.

O equilíbrio é a base da educação, é a busca de outro mundo possível para a vida com qualidade. A educação ambiental é uma forma de intervenção no mundo, "prática de liberdade", ato político e principal instrumento de mudança na "busca de outro mundo possível" (FREIRE, 2004, p. 19). Trata-se de um instrumento para alcançar a sustentabilidade dos conhecimentos tradicionais associados à biodiversidade amazônica.

O ser humano não pode mais continuar agindo como se os recursos naturais fossem inesgotáveis e que o equilíbrio do planeta não esteja ameaçado por essa exploração desenfreada e sem limites. Objetiva-se proteger a biodiversidade, essencial ao desenvolvimento sustentável do Brasil. É preciso descobrir de que forma a biodiversidade pode ser também um capital natural, que será utilizado pelos Estados e povos tradicionais amazônicos para gerir e estimular o próprio desenvolvimento sustentável.

É importante analisar e avaliar as peculiaridades dos povos tradicionais da Amazônia e as 
características que diferenciam os CTAs à biodiversidade amazônica, no sentido de desvelar a realidade de opressão desumanizante e insustentável, superando essas circunstâncias de vida e construindo como libertação, a possibilidade de alcançar a sustentabilidade pela educação ambiental.

Trata-se da educação como intervenção social para transformar a sociedade, com posicionamento crítico. Educação que supere a visão hegemônica, autoritária do mercado de acúmulo da riqueza, em vista da justiça socioambiental pela garantia dos direitos de cidadania, nos quais está o direito de todos a um ambiente sadio.

Urge analisar os instrumentos de educação ambiental capazes de contribuir para o alcance da sustentabilidade dos CTAs à biodiversidade amazônica. Parte-se do pressuposto de que o desenvolvimento socioambiental da Amazônia pode ser realizado pela educação por meio do reconhecimento do valor do meio ambiente para o ser humano, ao percebê-lo como o local onde as relações sociais se realizam e são por ele influenciadas. As políticas públicas relacionadas à educação ambiental deverão considerar o Estado, os arranjos institucionais e as peculiaridades dos CTAs e dos povos tradicionais da Amazônia.

A educação ambiental visa a uma nova consciência diante do consumo, uma nova postura que evite o desperdício, como também em uma mudança na participação democrática para a formulação de novos estilos de vida e a construção de futuros possíveis, sob a sustentabilidade ecológica e a equidade social.

É necessário um modelo de desenvolvimento para a Amazônia que inclua um novo valor ao meio ambiente, mais do que sua mera utilização econômica, mas a percepção de que ele é essencial à vida humana. Trata-se do novo valor cultural, social e político, a inclusão dos povos tradicionais amazônicos como os ribeirinhos, as quebradoras de coco babaçu, dentre outras comunidades que detém sua importância para a cultura da região e para a preservação do meio ambiente.

Loureiro (2009, p. 19) destaca formas de desenvolvimento para a Amazônia, como o aproveitamento dos bens naturais pelas comunidades e empresas; o aproveitamento dos saberes tradicionais e do artesanato; pesca artesanal; gestão dos recursos florestais e modernização do extrativismo; turismo ecológico e cultural. Sachs (2002, p. 25) propõe desenvolvimento pela biomassa que consiste na transformação do conhecimento dos povos, Biodiversidade produz biomassa pela biotecnologia.

O conhecimento que é fornecido principalmente pela educação ambiental, que permite uma mudança de valoração do meio ambiente e sua existência para além das necessidades humanas, mas como um condicionamento das relações sociais. Urge uma nova forma de interagir ao meio ambiente e a educação é o principal instrumento de mudança a fim de permitir analisar as peculiaridades dos povos tradicionais da Amazônia e dos CTAs à biodiversidade amazônica, 
transmitidos de geração a geração.

A educação ambiental é forma de alcançar a sustentabilidade dos CTAs à biodiversidade amazônica. Na perspectiva da dimensão ambiental, educar para preservar e potencializar a diversidade natural e cultural.

A dimensão econômica relaciona-se à educação ambiental no sentido de pensar processos que respeitem as diferentes realidades sociais e dos ecossistemas, minimizando os impactos. A educação ambiental interage com a dimensão social ao assegurar o acesso igualitário aos bens naturais e culturais. Implica materializar, no mundo fático, o que já se encontra positivado na CRFB, carente de maior despertar da sociedade brasileira para o tema.

O alcance da sustentabilidade dos CTAs à biodiversidade amazônica demanda outra abordagem de conteúdos e metodologia no processo educativo, superando uma educação ambiental conservacionista e preservacionista, avançando para uma visão emancipatória. Portanto, educar para a sustentabilidade é uma educação para outro mundo possível.

\section{CONCLUSÃO}

O trabalho em testilha constatou a imprescindível inter-relação dos conhecimentos tradiconais dos povos da Amazônia com a conservação ambiental, sob o viés do alcance da sustentabilidade no tratamento dos conhecimentos tradicionais associados à biodiversidade amazônica.

O trabalho requereu um esquema conceitual que lhe conferiu um instrumental teórico suficientemente articulado para a sua problemática. Foi utilizado o método indutivo na fase de investigação e na fase de tratamento dos dados. Nas diversas fases da pesquisa foram acionadas as técnicas do referente, da categoria, do conceito operacional, da pesquisa bibliográfica e do fichamento.

O trabalho evidenciou que a dimensão ambiental da sustentabilidade é a "capacidade de uma dada população de ocupar uma determinada área e explorar seus recursos naturais sem ameaçar, ao longo do tempo, a integridade ecológica do meio ambiente" (LIMA e POZZOBON, 2005, p. 45). Os problemas relacionados à dimensão ambiental são os riscos à biodiversidade.

Na concepção de Garcia (2011, p. 40) a dimensão econômica da sustentabilidade trata do desenvolvimento da economia com a finalidade de gerar melhoria na qualidade de vida das pessoas, com padrões que contenham o menor impacto ambiental possível. Os problemas associados à dimensão econômica são a biopirataria e a apropriação indevida dos conhecimentos tradicionais.

A dimensão social da sustentabilidade é o capital humano, aspecto social relacionado às qualidades dos seres humanos. Baseada no processo de melhoria da qualidade de vida da sociedade, pela redução das discrepâncias entre a opulência e a miséria, como nivelamento de padrão de renda, 
acesso à educação, moradia, alimentação, ou seja, da garantia mínima dos direitos sociais previstos na CRFB. Os problemas relacionados à dimensão social referem-se à saúde e a qualidade de vida dos povos tradicionais da Amazônia.

O problema do trabalho em tela concentrou seus esforços no alcance da sustentabilidade no tratamento dos conhecimentos tradicionais associados à biodiversidade amazônica.

Para o alcance da sustentabilidade dos conhecimentos tradicionais associados à biodiversidade amazônica sugeriu-se: a cooperação, a solidariedade, o equilíbrio e a educação ambiental. Cooperação é instrumento para proteger direitos humanos e integra países. Possibilita a conservação e utilização sustentável dos conhecimentos tradicionais associados. No cenário internacional de interdependência Kinoshita (1999, p. 57) explica que há “dever de cooperação para atingir o desenvolvimento mundial".

Ferrer (2012, p. 77) compreende que a sociedade global impõe a "preminencia de la solidaridad planetaria en nuestras relaciones, (...) el Derecho público (...) que impone la solidaridad colectiva por encima de los intereses parciales o individuales. Ese es el fundamento del derecho de la sostenibilidad".

O equilíbrio é a base da educação, é a busca de outro mundo possível para a vida com qualidade. O desrespeito ao equilíbrio da natureza cobra altíssimo preço. Para Gadotti (2000, p. 78) o "equilíbrio dinâmico com o outro e com o meio, (...) é harmonia entre os diferentes" e sugestão de alcance da sustentabilidade.

A educação ambiental é uma forma de intervenção no mundo, "prática de liberdade", ato político e principal instrumento de mudança na "busca de outro mundo possível” (FREIRE, 2004, p. 19). Trata-se de um instrumento para alcançar a sustentabilidade dos conhecimentos tradicionais associados à biodiversidade amazônica.

Com vistas a esse fim, percorreu-se, do ponto de vista do marco de referência, a bibliografia de relevância já tornada pública em relação ao tema de estudo. O equacionamento do problema suscitou na hipótese de que a floresta amazônica está inserida além do Brasil, em territórios de outros países sul-americanos como Suriname, Venezuela, Guiana, Colômbia, Equador, Peru e Bolívia, além da Guiana Francesa, portanto, sua conservação exige, necessariamente, o compromisso e a organização de todos esses países.

O presente trabalho atingiu o objetivo geral que foi sugerir o alcance da sustentabilidade no tratamento dos conhecimentos tradicionais associados à biodiversidade amazônica.

O trabalho cumpriu os objetivos específicos propostos, a saber: estudou as dimensões ambiental, econômica e social da sustentabilidade dos conhecimentos tradicionais associados à biodiversidade amazônica; enfatizou os riscos à biodiversidade amazônica, a biopirataria, a 
apropriação indevidade dos conhecimentos tradicionais, a saúde e a qualidade de vida dos povos tradicionais da Amazônia, ou seja, os problemas relacionados às dimensões da sustentabilidade; sugeriu o alcance da sustentabilidade no tratamento dos conhecimentos tradicionais associados à biodiversidade amazônica, por meio da cooperação, do equilíbrio e da educação ambiental.

\section{REFERÊNCIAS}

BOFF, Leonardo. Sustentabilidade: o que é - o que não é. Petrópolis-RJ: Vozes, 2012.

BOSSELMANN, Klaus. O princípio da sustentabilidade: transformando direito e governança. Tradução de Phillip Gil França. São Paulo: RT, 2015.

BRASIL. Decreto Legislativo n. 2, de 1994. Aprova o texto da Convenção sobre Diversidade Biológica. Disponível em: <http://www2.camara.leg.br/legin/fed/decleg/1994/decretolegisla tivo-2-3-fevereiro-1994-358280-publicacaooriginal-1-pl.html>. Acesso em: 20 dez. 2018.

CANOTILHO, Joaquim José Gomes. O princípio da sustentabilidade como princípio estruturante do Direito Constitucional. Revista de Estudos Politécnicos Polytechinical Studies Review, v. 8, n. 13, 2010. Disponível em: <http://www.scielo.oces.mctes.pt/ pdf/tek/n13/n13a02>. Acesso em: 16 jul. 2019.

COIMBRA, Wilber Carlos dos Santos. A tutela da sustentabilidade exercida pelos Tribunais de Contas como garantia de efetividade dos atos da Administração Pública. Tese (Doutorado em Ciência Jurídica). Curso de Doutorado em Ciência Jurídica, Universidade do Vale do Itajaí, Santa Catarina, 2017.

CRUZ, Paulo Márcio; BODNAR, Zenildo. Globalização, transnacionalidade e sustentabilidade. In: CRUZ, Paulo Márcio; BODNAR, Zenildo; FERRER, Gabriel Real; PRADO, Lucas de Melo (Orgs.). Livro eletrônico. Itajaí-SC: UNIVALI, 2012. Disponível em: $<$ http://www.univali.br/ppcj/ebook>. Acesso em: 19 jul. 2019.

O novo paradigma do Direito. Revista de Estudos Constitucionais, Hermenêutica e Teoria do Direito, v. 3, p. 75-83, Porto Alegre: RECHTD/UNISINOS, 2011.

CRUZ, Paulo Márcio; GLASENAPP, Maikon Cristiano. Governança e sustentabilidade: constituindo novos paradigmas na pós-modernidade. Revista Direito e Liberdade, Natal-RN, v. 16, n. 2, p. 163-186, mai./ago., 2014.

DERANI, Cristiane. Direito ambiental econômico. 3. ed. São Paulo: Saraiva, 2008.

DIAS, Bráulio Ferreira de Souza. A biodiversidade na Amazônia: uma introdução ao desconhecido. In: VELLOSO, João Paulo dos Reis; ALBUQUERQUE, Roberto Cavalcanti de (Coord.). Amazônia, vazio de soluções? Desenvolvimento moderno baseado na biodiversidade. Rio de Janeiro: José Olympio, 2002.

DUTFIELD, Graham. Repartindo benefícios da biodiversidade: qual o papel do sistema de patentes? In: VARELLA, Marcelo Dias; PLATIAU, Ana Flávia Barros. Diversidade biológica 
e conhecimentos tradicionais, p. 57-107. Belo Horizonte: Del Rey, 2004.

EMERY, Emerson Baldotto. Desenvolvimento sustentável: Princípio da Eficiência em procedimentos licitatórios. Belo Horizonte: Fórum, 2016.

FERRER, Gabriel Real. Calidad de vida, medio ambiente, sostentabilidad y cidadanía. Construímos juntos el futuro? Revista Novos Estudos Jurídicos - NEJ, Itajaí-SC, v. 17, n. 3, p. 310-326, set./dez., 2012. Disponível em: <http://siaiweb 06.univali.br/seer/index.php/nej/ article/view/4202>. Acesso em: 21 jul. 2019.

FREIRE, Paulo. Pedagogia da autonomia. Rio de Janeiro: Paz e Terra; Anca/MST, 2004.

FREITAS Juarez. Direito constitucional à democracia. In: FREITAS, Juarez; TEIXEIRA, Anderson V. (Orgs.). Direito à democracia: ensaios transdisciplinares. São Paulo: Conceito, 2001.

Sustentabilidade: direito ao futuro. 2. ed. Belo Horizonte: Fórum, 2012.

FREITAS, Thiago Pereira de. Sustentabilidade e as contratações públicas. Rio de Janeiro: Lumen Juris, 2014.

GADOTTI, Moacir. Pedagogia da terra. 2. ed. São Paulo: Cortez, 2000.

GARCIA, Denise Schmitt Siqueira. GARCIA, Denise Schmitt Siqueira. El principio de sostenibilidad y los puertos: a atividade portuária como garantidora da dimensão econômica e social do princípio da sustentabilidade. 2011.451 f. Tese. (Doctorado em Derecho Ambiental y Sostenibilidad de la Universidad de Alicante - UA). Espanha, Universidade de Alicante, 2011.

GUATTARI, Félix. As três ecologias. Título original: Les trois écologies. Tradução de Maria Cristina F. Bittencourt. Campinas: Papirus, 1990.

JAMIESON, Dale. Ética e meio ambiente: uma introdução. Tradução de André Luiz de Alvarenga. São Paulo: SENAC, 2010.

KEOHANE, Robert O. After Hegemony: cooperation and discord in the world political economy. Estados Unidos: Princeton University Press, 2005.

KINOSHITA, Fernando. El tratado de libre comercio entre la Unión Europea y el Mercosur: consolidación de un marco jurídico-económico internacional. Tesis Doctoral. Madrid: Universidad Pontificia Comillas/ICADE, 1999.

LAPLANTE, Julie. Pouvoir guérir: médecines autochtones et humanitaires. Laval: Les Presses de l'Université Laval, 2004.

LIMA, Deborah; POZZOBON, Jorge. Amazônia socioambiental. Sustentabilidade ecológica e diversidade social, v. 19, n. 54, São Paulo, mai./ago., 2005. Disponível em: $<$ http://www. scielo.br/scielo.php?pid=S0103-142005000200004\&script $=$ sci_arttext $>$. Acesso em: 17 jul. 2019. 
LOUREIRO, Violeta Refkalefsky. A Amazônia no século XXI: novas formas de desenvolvimento. São Paulo: Empório do Livro, 2009.

MARTÍN MATEO, Ramón. La revolución ambiental pendiente. In: PIÑAR MAÑAS, José Luis. Desarrollo Sostenible y protección del medio ambiente. Civitas: Madrid, 2002.

NEVES, Lafaite Santos. Sustentabilidade: anais de textos selecionados do $5^{\circ}$ seminário sobre sustentabilidade. Curitiba-PR: Juruá, 2011.

SACHS, Ignacy. Caminhos para o Desenvolvimento Sustentável. Rio de Janeiro: Garamond, 2002.

VIEIRA, Paulo Freire (Org.). Rumo à Ecossocioeconomia. Teoria e Prática do Desenvolvimento. São Paulo: Cortez, 2007.

SANTILLI, Juliana. Patrimônio imaterial e direitos intelectuais coletivos. In: MATHIAS, Fernando; NOVIUON, Henry de (Org.). As encruzilhadas da modernidade: debate sobre biodiversidade, tecnociência e cultura. São Paulo: Instituto Socioambiental, 2006.

SILVA, José Afonso da. Direito Ambiental Constitucional. 8. ed. São Paulo: Malheiros, 2010.

SILVEIRA, Jane Simoni. A multidimensionalidade de produtos locais: implicações para políticas públicas, mercado, território e sustentabilidade na Amazônia. Tese de Doutorado. Centro de Desenvolvimento Sustentável. Universidade de Brasília, Brasília, 2009. Disponível em: <https://core.ac.uk/download/pdf/33534939.pdf>. Acesso em: 22 ago. 2017.

SOUZA, Maria Claudia da Silva Antunes de; REZENDE, Elcio Nacur (Orgs.). Sustentabilidade e meio ambiente: efetividades e desafios. Belo Horizonte-MG: D’Plácido, 2017.

STEFANELLO, Alaim G. F. A propriedade intelectual como instrumento jurídico internacional de exploração: a luta do direito socioambiental contra a biopirataria. Revista de Direito da ADVOCEF, Londrina, v. 1, n. 1, p. 185-197, ago., 2005. 